Military Technical College Kobry Elkobbah, Cairo, Egypt.

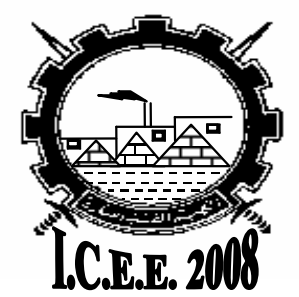

$4^{\text {th }}$ International Conference On Chemical \& Environmental Engineering

\title{
HYDROISOMERIZATION OF $n$-HEXANE USING UNLOADED AND LOW PLATINUM LOADED H-ZSM-5 AND H-MOR CATALYSTS
}

\author{
A.K. Aboul-Gheit ${ }^{*}$, S.M. Abdel-Hamid, D.S. El-Desouki
}

\begin{abstract}
The applicability for investing and comparing two zeolites (H-ZSM-5 and H-MOR) as supports for low-platinum, less-expensive, catalysts for the hydroisomerization of nparaffins in petroleum naphtha is investigated. $\mathrm{n}$-Hexane was used as a model nparaffin feed at temperatures of $250-500^{\circ} \mathrm{C}$ in a pulsed reactor in hydrogen flow at atmospheric pressure. The H-ZSM-5 zeolite acquires higher density of strong acid sites which are still less strongly acidic than H-MOR. These somewhat milder acid sites enhance hydroisomerization after incorporating $0.15 \% \mathrm{Pt}$. Moreover, hydrochlorination and hydrofluorination of the $0.15 \% \mathrm{Pt} / \mathrm{H}-\mathrm{ZSM}-5$ catalyst were carried out for modifying its acidity hoping to maximize its hydroisomerization activity. Furthermore, the effect of this hydrohalogenation treatment on other hydroconversion reactions (hydrocracking and dehydrocyclization) was investigated. The $\mathrm{HCl}$ treatment has significantly enhanced the required catalytic functions, whereas HF appears mostly deteriorative.
\end{abstract}

KEY WORD: n-hexane, hydroisomerization, hydrocracking, dehydrocyclization, H-ZSM-5, H-MOR, hydrohalogenation.

Egyptian Petroleum Research Institute, Process Development Department, Nasr City, Cairo 11787,

Egypt, E-mail: aboulgheit2000@hotmail.com 


\section{INTRODUCTION}

The hydroisomerization of $n$-paraffins is a process of prime importance for the upgrading of paraffinic low-octane naphtha for producing high-octane $\mathrm{C}_{5}{ }^{+}$gasoline. Various modifications have been carried out to improve the hydroisomerization catalysts in this laboratory. A great effort has been directed to modify zeolite supports in these catalysts via strengthening or creating stronger acid sites, compared to the traditionally used $\mathrm{y}$-alumina catalytic support.

The hydroisomerization of $n$-hexane has been studied using $0.35 \% \mathrm{Pt}$ supported on H-MOR or NH4-MOR steamed before or after Pt incorporation [1,2]; where maximum hexane isomers amounted to $59.0 \%$ at $275^{\circ} \mathrm{C}$. Shifting to using $\mathrm{H}-\mathrm{ZSM}-5$ zeolite support loaded with $0.30 \% \mathrm{Pt}$ gives $71.8 \%$ isohexanes at $325^{\circ} \mathrm{C}$ when dealuminated with EDTA [3]. Again, n-hexane was isomerized on $\mathrm{Pt} / \mathrm{H}-\mathrm{MOR}$ and $\mathrm{Pt} / \mathrm{BEA}$ catalysts with various $\mathrm{Pt}$ contents and bimetallic Pt-Pd/H-MOR, Pt-Pd/H-BEA, Pt-Ir/H-MOR and $\mathrm{Pt}-\mathrm{Ir} / \mathrm{H}-\mathrm{BEA}$, with various secondary metal contents [4]. The addition of $\mathrm{Pd}$ (activation promoter) to $\mathrm{Pt}$ has increased the metals dispersion in both zeolites up to a certain content, whereas Ir (promoter for counter-deactivation by coke deposition) has decreased the metal dispersion. n-Hexane hydroisomerization was significantly promoted with the doping of fluoride ion on catalysts containing Pt, Ir, Pt-Re and Pt-U supported on $\mathrm{y}$-alumina [5].

In the present work, a catalyst containing low-Pt content $(0.15 \%)$ loaded on $\mathrm{H}-\mathrm{ZSM}-5$ has been doped with $3 \% \mathrm{HCl}$ or $\mathrm{HF}$; the former acid has been a significantly successful promoter, whereas the latter has mostly acted as an inhibitor.

\section{EXPERIMENTAL}

\subsection{Preparation of the Unloaded Zeolite Catalysts (H-ZSM-5 and H-MOR)}

The Na-form of ZSM-5 and MOR zeolites were kindly provided by Süd-Chemie AG, Germany. They were exchanged in $0.7 \mathrm{M} \mathrm{NH}_{4} \mathrm{NO}_{3}$ solution five times; each time with a fresh solution for $8 \mathrm{~h}$ at $70^{\circ} \mathrm{C}$. The $\mathrm{NH}_{4}$-zeolite obtained was separated, washed with distilled water till free of the $\mathrm{NO}_{3}{ }^{+}$ion, dried at $110^{\circ} \mathrm{C}$ overnight then calcined in air at $530^{\circ} \mathrm{C}$ for $3 \mathrm{~h}$ to be deammoniated to $\mathrm{H}-Z \mathrm{SM}-5$ and $\mathrm{H}-\mathrm{MOR}$. The $\mathrm{Na}^{+}$content was less than $0.02 \mathrm{wt} \%$.

\subsubsection{Preparation of $0.15 \% \mathrm{Pt} / \mathrm{H}-\mathrm{ZSM}-5$ and $0.15 \% \mathrm{Pt} / \mathrm{H}-\mathrm{MOR}$ catalysts}

Both catalysts were prepared using the impregnation method. A quantity of chloroplatinic acid, necessary for loading $0.15 \mathrm{wt} \%$ of $\mathrm{Pt}$ metal in each catalyst $(0.15 \% \mathrm{Pt} / \mathrm{H}-\mathrm{ZSM}-5$ or $0.15 \% \mathrm{Pt} / \mathrm{H}-\mathrm{MOR})$ was dissolved in distilled water. This solution was adjusted to cover the zeolite in a beaker and left for $24 \mathrm{~h}$ at room temperature. The catalyst was then dried at $110^{\circ} \mathrm{C}$ overnight then calcined in air for $4 \mathrm{~h}$ at $530^{\circ} \mathrm{C}$ and reduced at $500^{\circ} \mathrm{C}$ in $\mathrm{H}_{2}$ flow of $20 \mathrm{~cm}^{3} \mathrm{~min}^{-1}$ in a flow reactor for $8 \mathrm{~h}$. 


\subsection{Hydrochlorination and Hydrofluorination of the $0.15 \% \mathrm{Pt} / \mathrm{H}-\mathrm{ZSM}-5$ Catalyst}

A part of the calcined $0.15 \% \mathrm{Pt} / \mathrm{H}-\mathrm{ZSM}-5$ catalyst was doped with an aqueous solution containing $3.0 \mathrm{wt} \%$ of $\mathrm{HCl}$ or $\mathrm{HF}$ relative to the catalysts weights. The catalysts were dried at $110^{\circ} \mathrm{C}$ overnight then calcined in air at $530^{\circ} \mathrm{C}$ for $3 \mathrm{~h}$. Before carrying out the hydroconversion runs, the catalysts were heated in the catalytic reactor at $500^{\circ} \mathrm{C}$ for $2 \mathrm{~h}$ in a flow of $20 \mathrm{~cm}^{3} \mathrm{~min}^{-1}$ of pure hydrogen gas. It is to be noticed that $\sim 70 \%$ and $\sim 84 \%$ of the $\mathrm{Cl}^{-}$and $\mathrm{F}^{-}$ions, respectively, (determined by ionchromatography) of the doped haloacids, remained in $0.15 \% \mathrm{Pt} / \mathrm{H}-\mathrm{ZSM}-5(\mathrm{HCl})$ and $0.15 \% \mathrm{Pt} / \mathrm{H}-\mathrm{ZSM}-5$ (HF) catalysts, respectively, after drying, calcination and reduction. This indicates a higher stability of the fluorine-zeolite bonding than the chlorinezeolite bonding under the applied dry conditions.

\section{3. n-Hexene Hydroconversion, Reactor System and Analysis}

A stainless-steel microcatalytic tubular pulse reactor, containing $0.2 \mathrm{~g}$ of a catalyst, was used. The reactor was thermostated to $\pm 1^{\circ} \mathrm{C}$. Hydrogen was used as a carrier gas and simultaneously as a reactant, at a flow rate of $20 \mathrm{~cm}^{3} \mathrm{~min}^{-1}$ in all runs. $\mathrm{n}$ Hexane feed pulses of $1.0 \mu \mathrm{l}$ were always injected into the carrier $\mathrm{H}_{2}$ flow passing into the inlet of the reactor which passes to OV-101 column for analysis.

\subsection{Temperature Programmed Desorption (TPD) of $\mathrm{NH}_{3}$}

The TPD procedure by Aboul-Gheit [6,7] using highly sensitive (gold sensor) differential scanning calorimetry (DSC) has been applied for detecting and evaluating the desorption of presorbed ammonia from the acid sites of the current catalysts. Ammonia was initially adsorbed on the catalyst in a silica-tube furnace till saturation then desorbed in a Mettler TA-3000 DSC unit in a continuous current of purest $\mathrm{N}_{2}$. The thermogram obtained for each catalyst gives two peaks; a low-temperature (LT) peak corresponding to enthalpy $\left(\Delta \mathrm{H}_{\text {des }}\right)$ of ammonia desorption from the weak acid sites of the catalyst and a high temperature $(\mathrm{HT})$ peak corresponding to $\Delta \mathrm{H}_{\text {des }}$ of ammonia desorbed from the strong acid sites. The $\Delta H_{\text {des }}$ values are proportional to the number of acid sites, whereas the peak temperature $\left(T_{\max }\right)$ correlates the acid sites strength in the catalyst (Fig. 1). The TPD data obtained to evaluate strong acid sites are given in Table 1.

\subsection{Dispersion of Platinum in the Catalysts}

The dispersion of $\mathrm{Pt}$ in the current catalysts, were determined by hydrogen chemisorption using Freel's pulse technique [8]. The calcined catalyst was heated in the furnace at $500^{\circ} \mathrm{C}$ for $3 \mathrm{~h}$ at a flow of $50 \mathrm{~cm}^{3} \mathrm{~min}^{-1}$ of ultra-pure hydrogen then using purest $\mathrm{N}_{2}$ at $500^{\circ} \mathrm{C}$ (degassing). After shutting off the furnace, hydrogen was pulsed into the $\mathrm{N}_{2}$ carrier gas till saturation, i.e, appearance of $\mathrm{H}_{2}$ peaks equivalent to complete volumes of unchemisorbed pulses. The hydrogen uptake was calculated as hydrogen atoms adsorbed per total $\mathrm{Pt}$ atoms. The $\mathrm{H} / \mathrm{Pt}$ stoichiometry of $1 / 1$ has been used. The data obtained are given in Tables 1 and 2. 


\section{RESULTS AND DISCUSSION}

\subsection{Hydroconversion of N-Hexane Using Unloaded and Pt-Loaded Zeolites}

The activities of the H-MOR and H-ZSM-5 zeolites as catalyst for the hydroconversion of $\mathrm{n}$-hexane at temperatures of $250-500^{\circ} \mathrm{C}$ and under atmospheric pressure, in a pulsed type microreactor using $\mathrm{H}_{2}$ flow of $20 \mathrm{~cm}^{3} \mathrm{~min}^{-1}$ are shown in Fig. 2a. Evidently, H-ZSM-5 is much less active than H-MOR; the conversion of n-hexane using the former catalyst ranges between 0.8 and $35.2 \%$ at reaction temperatures of $300-500^{\circ} \mathrm{C}$, respectively, whereas using the latter catalyst, conversion is $12.0-96.1 \%$ at temperatures of $275-500^{\circ} \mathrm{C}$, respectively.

The conversion of $n$-hexane using $\mathrm{H}-\mathrm{ZSM}-5$ catalyst is attributed only to hydrocracking reactions, where $\mathrm{C}_{2}, \mathrm{C}_{3}$ and $\mathrm{C}_{4}$ components (iso-and n-butanes) are obtained. Iso-hexanes and benzene have not been detected among products. Methane is also assumed to be absent since $\mathrm{C}_{5}$ components are absent. Hydrogenolysis to methane is a catalytic property of the metal function in dualfunctional catalysts. However, the significantly higher activity of the H-MOR catalyst is attributed to its higher acid strength (Table 1). On this catalyst, hexane isomers are also present in trace amounts. The hydrocracked products contain iso- and n-butane as well as iso- and n-pentane, together with $\mathrm{C}_{1+} \mathrm{C}_{2}, \mathrm{C}_{3}$, iso- and n-butanes. Moreover, benzene is produced at higher temperatures, i.e., $1.1-3.7 \%$ at $375-500^{\circ} \mathrm{C}$, respectively.

It has to be pointed out that almost all hydrocracking products using the unloaded $\mathrm{H}$ ZSM-5 and H-MOR zeolites as catalysts (in absence of metals) are saturated hydrocarbons. In the early work of Platteauw et al. [9], it has been assumed that amorphous $\mathrm{SiO}_{2}-\mathrm{Al}_{2} \mathrm{O}_{3}$ catalyst possessed a "self-hydrogenating capability" accomplished via hydrogen-transfer for a period of time, even in absence of added hydrogen. Also, Aboul-Gheit et al. [10] has found that unloaded $\gamma$-alumina and $\mathrm{H}$ MOR zeolite as catalysts [11] possessed self hydrogenating capability. Furthermore, Sano et al. [12] found that H-ZSM-5 zeolite is active as a hydrogenation catalyst. At $535^{\circ} \mathrm{C}$, they have been able to convert $\approx 95 \%$ of ethene to ethane and concluded that hydrogenation takes place on the acid sites in absence of a metal. Also, Kanai et al. [13] shows that Brönsted acid sites become active hydrogenation sites of alkenes at higher temperatures. Furthermore, Chu et al. [14] state that in absence of active metal the acid centres of H-BEA zeolite themselves have hydrogenationdehydrogenation activities.

\subsubsection{Hydroconversion of $n$-hexane using $0.15 \% \mathrm{Pt} / \mathrm{H}-\mathrm{MOR}$ and $0.15 \% \mathrm{Pt} / \mathrm{H}$ - ZSM -5 catalysts}

The hydroconversion activity of $n$-hexane at temperatures of $275-500^{\circ} \mathrm{C}$ is found to range between 60.6 and $99.0 \%$ on a catalyst containing $0.15 \% \mathrm{Pt} / \mathrm{H}-\mathrm{MOR}$, and between 36.0 and $77.5 \%$, respectively, on a catalyst containing $0.15 \% \mathrm{Pt} / \mathrm{H}-\mathrm{ZSM}-5$ (Fig. 2b). Hydroconversion using the H-MOR catalyst has not been significantly enhanced by platinum incorporation, compared to the activity of $0.15 \% \mathrm{Pt} / \mathrm{H}-\mathrm{ZSM}-5$ 
(compare Figs. 2a and 2b). n-Hexane hydroconversion includes hydroisomerization that takes place at low reaction temperatures, together with hydrocracking and dehydrocyclization to benzene at higher temperatures.

\subsubsection{Hydroisomerization of $n$-hexane using $0.15 \% \mathrm{Pt} / \mathrm{H}-\mathrm{MOR}$ and $0.15 \% \mathrm{Pt} / \mathrm{H}$ - ZSM -5 catalysts}

Normally, n-paraffins are present as major components in the petroleum naphtha fractions. These paraffins acquire low octane numbers, e.g., n-hexane, n-heptane and $n$-octane have octane numbers of 26 , zero, and a negative octane number, respectively. Hence, upgrading of straight-run naphtha via the hydroisomerization processes produces mixtures of higher-octane components and therefore, this refining process is indeed of prime commercial importance. In the present work, nhexane isomerization occurring on the current $0.15 \% \mathrm{Pt} / \mathrm{H}-\mathrm{MOR}$ and $0.15 \% \mathrm{Pt} / \mathrm{H}-\mathrm{ZSM}$ 5 catalysts, produces several branched isoparaffins acquiring varying octane numbers. However, the produced isohexanes are susceptible to undergo hydrocracking which is practically considered as a loss. Therefore, these cracked products have to be minimized.

Fig. 3 shows that the hexane isomers using the $0.15 \% \mathrm{Pt} / \mathrm{H}-\mathrm{MOR}$ catalyst are significantly lower than using the $0.15 \% \mathrm{Pt} / \mathrm{H}-\mathrm{ZSM}-5$ catalyst at $250^{\circ} \mathrm{C}(19.0 \%$ vs. $30.0 \%$ ). On the former catalyst, the isomers increase with temperature to reach a maximum of $38.1 \%$ at $275^{\circ} \mathrm{C}$, then rapidly decrease till disappear completely at $375^{\circ} \mathrm{C}$. However, using the $\mathrm{Pt} / \mathrm{H}-\mathrm{ZSM}-5$ catalyst, iso-hexanes increase gradually with temperature to reach a maximum of $41.3 \%$ at $350^{\circ} \mathrm{C}$ then decrease also gradually with further decreasing the temperature to reach $13.6 \%$ at $500^{\circ} \mathrm{C}$. This gradual increase and decrease of isomers with temperature can be attributed to the lower acid sites strength of the H-ZSM-5 component compared to H-MOR.

\subsubsection{Hydrocracking of $n$-hexane using $0.15 \% \mathrm{Pt} / \mathrm{H}-\mathrm{MOR}$ and $0.15 \% \mathrm{Pt} / \mathrm{H}-\mathrm{ZSM}-5$ catalysts}

Hydrocracking is a traditional competitor of hydroisomerisation. During the formation of an isomeric carbonium-ion, it may rupture (hydrocrack) before it acquires a hydride ion to form a stable isohexane molecule if the acidity strength of the catalyst and/or the temperature of reaction is high, because both isomerization and cracking reactions take place by the same mechanism (carbonium ion mechanism). Fig. 4 shows that on the $0.15 \% \mathrm{Pt} / \mathrm{H}-\mathrm{MOR}$ catalyst, hydrocracking starts with $2.7 \%$ at $275^{\circ} \mathrm{C}$ then sharply increases with temperature to reach as high as $98.2 \%$ at $375^{\circ} \mathrm{C}$, beyond which this reaction slightly slows down by a further increase of temperature to reach $95.1 \%$ at $500^{\circ} \mathrm{C}$. On the other hand, using the $0.15 \% \mathrm{Pt} / \mathrm{H}-\mathrm{ZSM}-5$, hydrocracking starts very mildly $(<1.0 \%)$ at $325^{\circ} \mathrm{C}$ and increases relatively slowly with temperature to reach $46.9 \%$ at $500^{\circ} \mathrm{C}$. The hydrocracking activities of the $0.15 \% \mathrm{Pt} / \mathrm{H}-\mathrm{ZSM}-5$ and $0.15 \% \mathrm{Pt} / \mathrm{H}-\mathrm{MOR}$ catalysts are compatible with the acid sites strength of these catalysts (Table 1). These data show the possible commercial applicability of the $0.15 \% \mathrm{Pt} / \mathrm{H}-\mathrm{MOR}$ catalyst in petroleum fractions hydrocracking processes at relatively low temperatures. 


\subsubsection{Dehydrocyclization of $n$-hexane using $0.15 \% \mathrm{Pt} / \mathrm{MOR}$ and $0.15 \% \mathrm{Pt} / \mathrm{H}$ - ZSM-5 catalysts:}

The dehydrocyclization of n-hexane to benzene (Fig.5) on $\mathrm{Pt} / \mathrm{H}-\mathrm{ZSM}-5$ catalyst starts with $2.4 \%$ at $350^{\circ} \mathrm{C}$ and increases gradually to reach $17.1 \%$ at $500^{\circ} \mathrm{C}$, whereas on the $\mathrm{Pt} / \mathrm{H}-\mathrm{MOR}$ catalyst, benzene formation is much lower. Correlation of Figs. 4 and 5 shows that although the hydrocracking activity of the $\mathrm{Pt} / \mathrm{H}-\mathrm{ZSM}-5$ catalyst is much lower than that of $\mathrm{Pt} / \mathrm{H}-\mathrm{MOR}$, the dehydrocyclization activity of the latter catalyst is much lower than that of the $\mathrm{Pt} / \mathrm{H}-\mathrm{ZSM}-5$ catalyst. Although hydrocracking is primarily dependent on the catalytic acid site strength, dehydrocyclization is primarily dependent on the catalytic metallic sites. In both catalysts, the metal component is apparently the same $(0.15 \mathrm{wt} \%$ platinum $)$. Hence, it is not the quantity of the metal that affects or control the dehydrocyclization activity. It is the state of the metallic sites in the catalyst. Primarily, the dispersion of $\mathrm{Pt}$ (fraction of $\mathrm{Pt}$ exposed) in the zeolite which amounts to $71.6 \%$ in $0.15 \% \mathrm{Pt} / \mathrm{MOR}$ and $79.6 \%$ in $0.15 \% \mathrm{Pt} / \mathrm{H}-\mathrm{ZSM}-5$. Nevertheless, the relatively very low $\mathrm{Pt}$ content in the current catalysts makes the zeolitic component much more significantly controlling.

This significantly lower activity of the $\mathrm{Pt} / \mathrm{H}-\mathrm{MOR}$ catalyst for benzene production than $\mathrm{Pt} / \mathrm{H}-\mathrm{ZSM}-5$ catalyst can not be attributed to the effect of the window size of the zeolite, since MOR is a large pore zeolite with a ring major chemical size of twelve, whereas ZSM-5 is a medium pore zeolite with 10 membered ring. Therefore, diffusion of the aromatic ring with $6.3 \AA$ diameter cannot be the limiting step in benzene formation in neither H-ZSM-5 nor in H-MOR catalyst. However, with straight channel of the ZSM-5 zeolite, diffusion is five times faster than in its sinusoidal channel for molecules close in size to the diameter of the pores, i.e., benzene. This slower diffusion cannot be a handicap, but it will be more effective for contacting the nhexane molecules with the largest possible number of active sites in these sinusoidal channels of ZSM-5. Furthermore, the pores of ZSM-5 are of tridirectional structure, whereas MOR acquires unidirectional channel structure [15].

The role of diffusion is aimed here to be clarified because it requires more clarification, since the $\mathrm{Pt}$ content in both catalysts is equal $(0.15 \mathrm{wt} \%)$, but the acid sites strength is higher in $\mathrm{Pt} / \mathrm{H}-\mathrm{MOR}$ than in $\mathrm{Pt} / \mathrm{H}-\mathrm{ZSM}-5$ (Table 1). In the former catalyst, the strong acid sites peak covers a temperature range of $388-608^{\circ} \mathrm{C}$ with a maximum at $505^{\circ} \mathrm{C}$, whereas in the latter catalyst this peak covers a temperature range of $332-588^{\circ} \mathrm{C}$ with maximum at $469^{\circ} \mathrm{C}$. Basically, the higher the temperature of the ammonia desorption, the higher the acid site strength. So, the higher conversion of $\mathrm{n}$-hexane to benzene on $0.15 \% \mathrm{Pt} / \mathrm{H}-\mathrm{ZSM}-5$ than $0.15 \% \mathrm{Pt} / \mathrm{H}-\mathrm{MOR}$ can be attributed to the effect of difference in diffusion and adsorption of the formed benzene molecules due to hydrophilicity-hydrophobicity characteristics.

\subsubsection{Effect of hydrohalogenation of the $0.15 \% \mathrm{Pt} / \mathrm{H}-\mathrm{ZSM}-5$ catalyst on its catalytic activities}

Although the number of acid sites in the $0.15 \% \mathrm{Pt} / \mathrm{H}-\mathrm{ZSM}-5$ catalyst is larger than in $0.15 \% \mathrm{Pt} / \mathrm{H}-\mathrm{MOR}$, the strength of these acid sites is weaker in the former catalyst 
(Table 2). Therefore, we examined the effect of hydrohalogenation of the $0.15 \% \mathrm{Pt} / \mathrm{H}-$ ZSM-5 catalyst on strengthening and/or increasing the number of its acid sites both analytically and catalytically on n-hexane hydroisomerization, hydrocracking and dehydrocyclization.

\subsubsection{Effect on $\mathrm{n}$-hexane hydroisomerization}

Figure 6 compares the hydroisomerization of $n$-hexane using the $0.15 \% \mathrm{Pt} / \mathrm{H}-\mathrm{ZSM}-5$ catalyst before and after its hydrohalogenation; i.e., the untreated catalyst is compared with its hydrochlorinated and hydrofluorinated versions. Evidently, hydrochlorination is the prosperous outlet, whereas hydrofluorination results in a negative effect. The former treatment, not only enhances $\mathrm{C}_{6}$ isomers production, but also results in lowering the temperature at which maximum isomerisation takes place $\left(61.7 \%\right.$ at $\left.300^{\circ} \mathrm{C}\right)$, whereas using the untreated catalyst version, the isomers maximum is $41.0 \%$ at $350^{\circ} \mathrm{C}$. Nevertheless, using the hydrofluorinated catalyst, maximum isomers dropped to $35 \%$ at a temperature of $350^{\circ} \mathrm{C}$. The hydrochlorination treatment, beside being a cheap one, it also lowers the operating temperature from 350 to $300^{\circ} \mathrm{C}$, which is a significantly economic addition.

The hydrochlorinating enhancement is attributed to: (1) acquiring a large number of moderately strong acid sites, strong enough for carbonium ions suitable for stable branching of the n-paraffin, (2) these acid sites, however, are not so strong that the isomerised carbonium ion doesn't crack. (3) hydrochlorination assists in increasing the dispersion of platinum (metal function in bifunctional catalysts) which is greatly important for balancing the strong acid function.

\subsubsection{Effect on $\mathbf{n}$-hexane hydrocracking}

Figure 7 shows that the hydrochlorination of the $0.15 \% \mathrm{Pt} / \mathrm{H}-\mathrm{ZSM}-5$ catalyst enhances the hydrocracking of n-hexane, whereas hydrofluorination doesn't measurably affect this reaction. The larger number of acid sites, possessing a moderate strength in the $0.15 \% \mathrm{Pt} / \mathrm{H}-\mathrm{ZSM}-5(\mathrm{HCl})$ catalyst (Table 1) gives mild cracking, particularly at the lower temperatures. Fortunately, hydrocracking of n-hexane using the current $\mathrm{HCl}$ treated catalyst (Fig. 6) amounts to as low as $3.5 \%$ of hydrocracked gases at $300^{\circ} \mathrm{C}$. At this temperature, the maximum isomerisation occurs, which is practically an important industrial parameter. Moreover, benzene is completely absent at $300^{\circ} \mathrm{C}$. Recently, the presence of benzene is medically forbidden in motor gasoline by modern environmental restrictions.

The work in this paper is primarily directed towards producing a significantly low $\mathrm{Pt}$ containing catalyst, cheaply treated with $\mathrm{HCl}$ acid. The low $\mathrm{Pt}$ content facilitates its high dispersion in the zeolite support, i.e., $\mathrm{D}=86.3 \%$, however, the untreated and the HF-treated catalysts acquire 78.6 and $65.8 \%$ dispersion, respectively. 


\subsubsection{Effect on $\mathbf{n}$-hexane dehydrocyclization}

The dehydrocyclization of $n$-hexane produces benzene at higher operation temperatures, since this reaction is an endothermic one. Using the untreated $\mathrm{Pt} / \mathrm{H}-$ ZSM-5 catalyst, benzene starts production of $2.5 \%$ at $350^{\circ} \mathrm{C}$ and increases with temperature to reach $17.1 \%$ at $500^{\circ} \mathrm{C}$, whereas using the $\mathrm{Pt} / \mathrm{H}-\mathrm{ZSM}-5(\mathrm{HCl})$ catalyst, benzene production starts with $1.2 \%$ at $325^{\circ} \mathrm{C}$ and increases as a function of temperature to reach $23.6 \%$ at $500^{\circ} \mathrm{C}$ (Fig. 8).

On these two catalysts, benzene formation shows some slowness at $400-500^{\circ} \mathrm{C}$ and $425-500^{\circ} \mathrm{C}$, respectively, indicating diffusion restriction of limited extent. However, using the $\mathrm{Pt} / \mathrm{H}-\mathrm{ZSM}-5$ (HF) catalyst, benzene formation is the lowest; it increases to reach a maximum of $8.5 \%$ at $425^{\circ} \mathrm{C}$, beyond which it declines with a further increase of temperature to reach $6.3 \%$ at $500^{\circ} \mathrm{C}$. This behaviour indicates that this reaction is significantly diffusion restricted, which is attributed to the leaching of Al and Si from the zeolite framework forming fluoroalumino- and fluorosilico- amorphous debris, which is deposited in the zeolitic channels causing diffusion restrication of the reactant and products along these channels.

The enhancement of benzene production on the $\mathrm{HCl}$ treated catalyst is attributed to enhancement of the acid sites number and strength beside enhancing the dispersion of $\mathrm{Pt}$ to a significant extent. However, although HF enhances the acid site strength, the activity for benzene formation is decreased significantly due to the decrease of $\mathrm{Pt}$ dispersion as well as the increase of diffusion restriction by the deposited debris.

\section{CONCLUSION}

$\mathrm{H}-\mathrm{ZSM}-5$ as a catalyst for $n$-hexane hydroconversion is found much less active than $\mathrm{H}-\mathrm{MOR}$; the latter is highly active for hydrocracking. Incorporation of $0.15 \% \mathrm{Pt}$ in $\mathrm{H}-$ ZSM-5 enhances n-hexane hydroisomerization but moderately enhances hydrocracking and dehydrocyclization. However, incorporation of $0.15 \% \mathrm{Pt}$ in $\mathrm{H}-\mathrm{MOR}$, doesn't enhance hydrocracking, which still remaining the major reaction; dehydrocyclization is poorly enhanced, while hydroisomerization is enhanced at lower temperatures. Doping of $\mathrm{Pt} / \mathrm{H}-\mathrm{ZSM}-5$ with $\mathrm{HCl}$ significantly enhances hydroisomerization, hydrocracking and dehydrocyclization, whereas doping with HF suppresses hydroisomerization and dehydrocyclization, but doesn't affect hydrocracking.

\section{REFERENCES}

[1] Aboul-Gheit, A.K., Ghoneim, S.A., Al-Owais, A.A., Appl. Catal., A, 170, 277 (1998).

[2] Aboul-Gheit, A.K., Ghoneim, S.A., Abdel-Hamid, S.M., Al-Owais, A.A., Erdỏl Erdgas Kohle, 115, \# 2, 90 (1999).

[3] Aboul-Gheit, A.K., Aboul-Gheit, N.A.K., Erdỏl Erdgas Kohle, 119, \# 1, 28 (2003). 
[4] Aboul-Gheit, A.K., Abdel-Hamid, S.M., Awadallah, A.E., Oil Gas Europ. Magaz. (Germ.), 30, \# 1, 40 (2004).

[5] Ali, A.A., Ali, L.I., Aboul-Fotouh, S. M., Aboul-Gheit, A.K., Appl. Catal., A, 215, 161 (2001).

[6] Aboul-Gheit, A.K., Thermochim. Acta, 191, 233 (1991).

[7] Aboul-Gheit, A.K., Solid State lonics, 101-103, 893 (1997).

[8] Freel, J.J., J. Catal., 25, 193 (1972).

[9] Platteeuw, J.C., Ruites, H., Van Zoonen, D., Kouwenhoven, H.W., Ind. Eng. Chem., Prod. Res. Develop., 6, 76 (1967).

[10] Aboul-Gheit, A.K., Menoufy, M.F., El-Fadly, A.M., Sif-El-Din, O.I., Sultan, S.A., J. Chem. Tech. Biotechnol., 32, 1000 (1982).

[11] Aboul-Gheit, A.K., Menoufy, M.F., El-Morsy, A.K., Abdel-Hamid, S.M., Zeolites, 7, 353 (1987).

[12] Sano, J., Hajiwara, H., Okaba, K., Saito, H., Takaya, H., Sekiyu Gakkaishi, 29, 89 (1986).

[13] Kanai, J., Martens, J.A., Jacobs, P.A., J. Catal., 133, 77 (1992).

[14] Chu, H.Y., Rosynek, M.P., Lunsford, J.H., J. Catal., 178, 352 (1998).

[15] Satterfield, C.N., Katzer, J.R., Vieth, W.R., Ind. Eng. Chem., Fundam., 10, 478 (1971). 
Table 1. Ammonia TPD from the Catalysts and Pt Dispersion in the Unloaded and $0.15 \%$ Pt-Loaded Zeolite Catalysts:

\begin{tabular}{|c|c|c|c|c|}
\hline \multirow{2}{*}{ Catalyst } & \multicolumn{2}{|c|}{ HT peak temperature, $\left.{ }^{\circ} \mathrm{C} \quad{ }^{*}\right)$} & \multirow{2}{*}{$\begin{array}{c}\Delta \mathbf{H}_{\text {des, }}, \mathbf{J g}^{-1} \\
\left({ }^{* *}\right)\end{array}$} & \multirow{2}{*}{$\begin{array}{c}\text { Pt Dispersion, } \\
\%\end{array}$} \\
\hline & Range, ${ }^{\circ} \mathrm{C}$ & Maximum, ${ }^{\circ} \mathrm{C}$ & & \\
\hline H-MOR & $400-620$ & 520 & 72 & --- \\
\hline H-ZSM-5 & $340-600$ & 480 & 115 & --- \\
\hline $0.15 \% \mathrm{Pt} / \mathrm{H}-\mathrm{MOR}$ & $388-610$ & 505 & 68 & 71.6 \\
\hline $0.15 \% \mathrm{Pt} / \mathrm{H}-\mathrm{ZSM}-5$ & $332-588$ & 469 & 95 & 79.6 \\
\hline
\end{tabular}

$\left({ }^{*}\right)$ Proportional to acid sites strength $\quad\left({ }^{* *}\right)$ Proportional to acid sites number

Table 2. Ammonia TPD from the Catalysts and Pt Dispersion in the $0.15 \% \mathrm{Pt} /$ Zeolite Catalysts before and after hydrohalogenation:

\begin{tabular}{|c|c|c|c|c|}
\hline \multirow[b]{2}{*}{ Catalyst } & \multicolumn{2}{|c|}{ HT peak temperature, ${ }^{\circ} \mathrm{C}\left({ }^{*}\right)$} & \multirow{2}{*}{$\underset{\left({ }^{* *}\right)}{\Delta \mathbf{H}_{\text {des }}, \mathbf{J g}^{-1}}$} & \multirow{2}{*}{$\begin{array}{c}\text { Pt } \\
\text { Dispersion, } \\
\%\end{array}$} \\
\hline & $\underset{{ }^{\circ} \mathrm{C}}{\text { Range, }}$ & Maximum, ${ }^{\circ} \mathrm{C}$ & & \\
\hline $0.15 \% \mathrm{Pt} / \mathrm{H}-\mathrm{ZSM}-5$ & $332-588$ & 469 & 95 & 78.6 \\
\hline $\begin{array}{c}0.15 \% \mathrm{Pt} / \mathrm{H}-\mathrm{ZSM}- \\
5(\mathrm{HCl})\end{array}$ & $337-592$ & 474 & 107 & 86.3 \\
\hline $\begin{array}{c}0.15 \% \mathrm{Pt} / \mathrm{H}-\mathrm{ZSM}- \\
5(\mathrm{HF})\end{array}$ & $341-596$ & 478 & 96 & 65.8 \\
\hline
\end{tabular}

$\left({ }^{*}\right)$ Proportional to acid sites strength $\quad\left({ }^{* *}\right)$ Proportional to acid sites number 


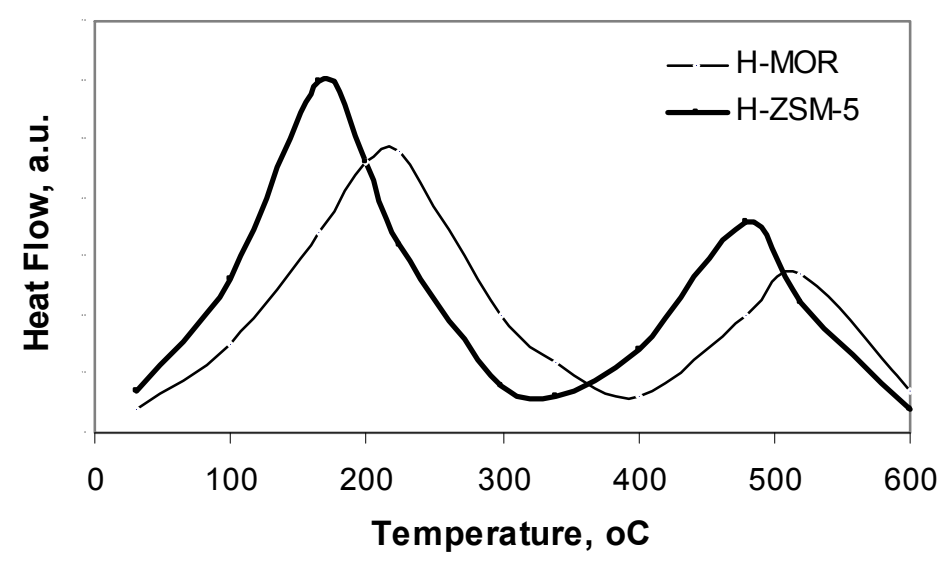

Fig. 1. TPD of ammonia from H-MOR and H-ZSM5 zeolites

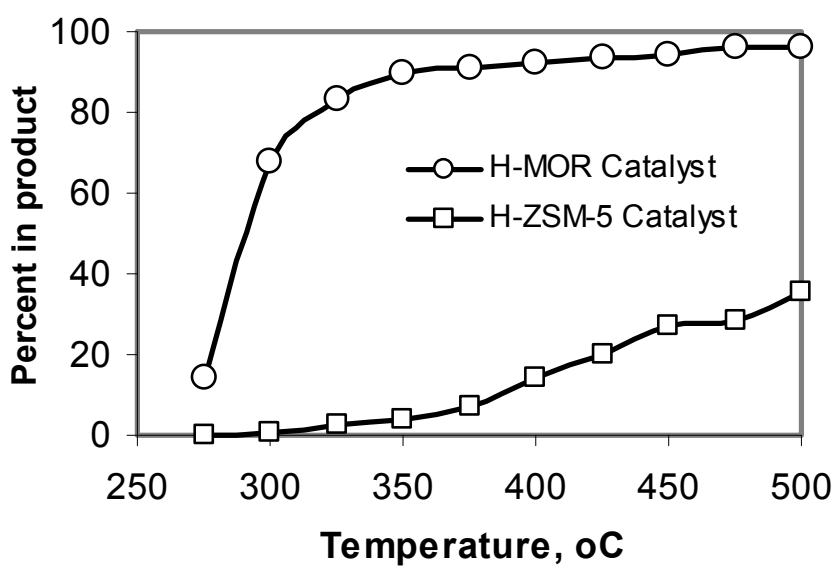

Fig. 2a. Hydroconversion of $n$-hexane on $\mathrm{H}-\mathrm{ZSM}-5$ and H-MOR catalysts

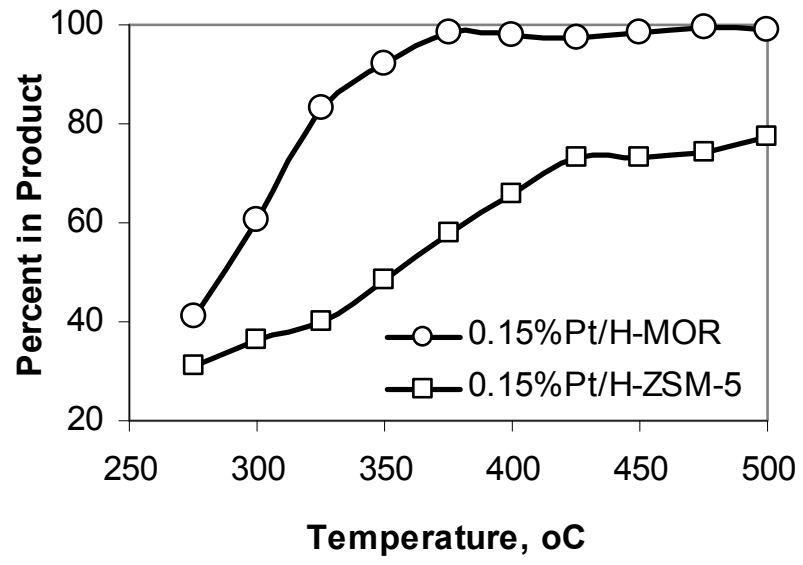

Fig. 2b. Hydroconversion of $n$-Hexane on $0.15 \%$ Pt-Loaded Zeolite Catalysts 


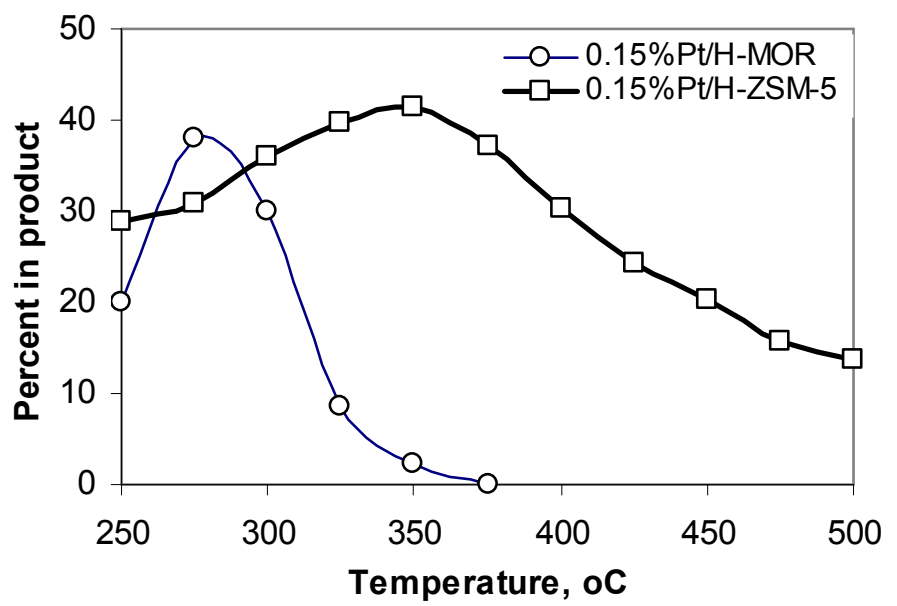

Fig. 3. Hydroisomerization of $n$-hexane on $0.15 \% \mathrm{Pt}$ loaded H-MOR and H-ZSM-5 catalysts

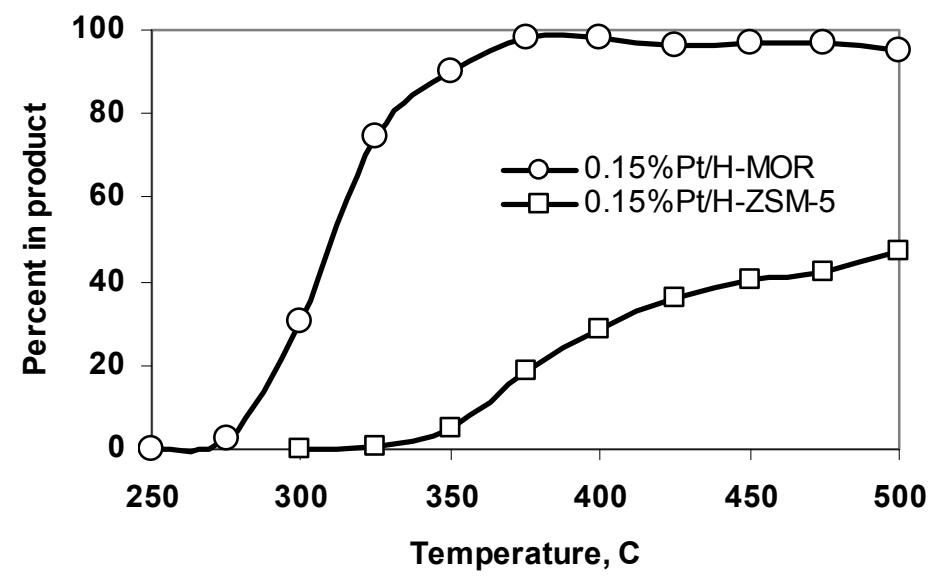

Fig. 4. Hydrocracking of $n$-hexane on $0.15 \% \mathrm{Pt}$ loaded on $\mathrm{H}-\mathrm{MOR}$ and $\mathrm{H}-\mathrm{ZSM}-5$ catalys ts

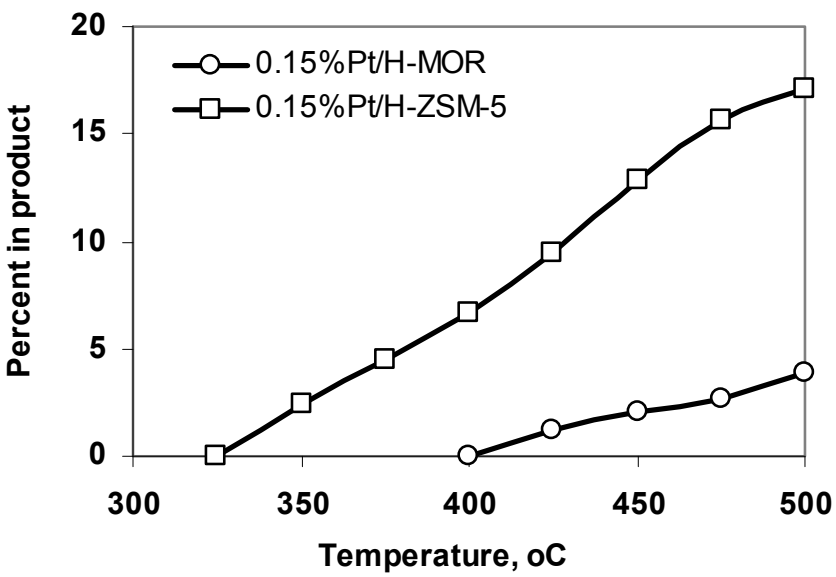

Fig. 5. Dehydrocyclization of $n$-hexane on $0.15 \% \mathrm{Pt}$ loaded H-MOR and H-ZSM-5 catalysts 


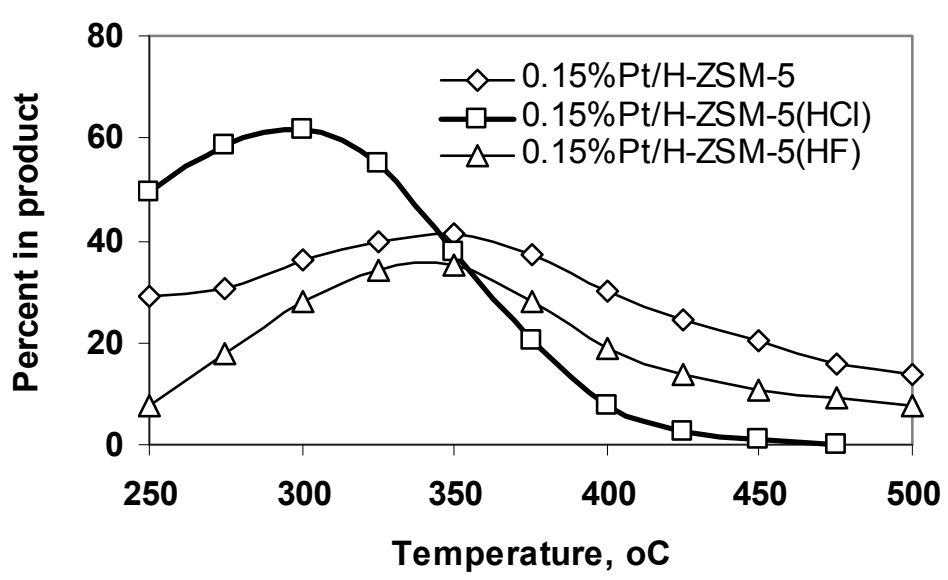

Fig. 6. n-Hexane hydroisomerization before and after $\mathrm{HCl}$ and $\mathrm{HF}$ treatment of the catalyst

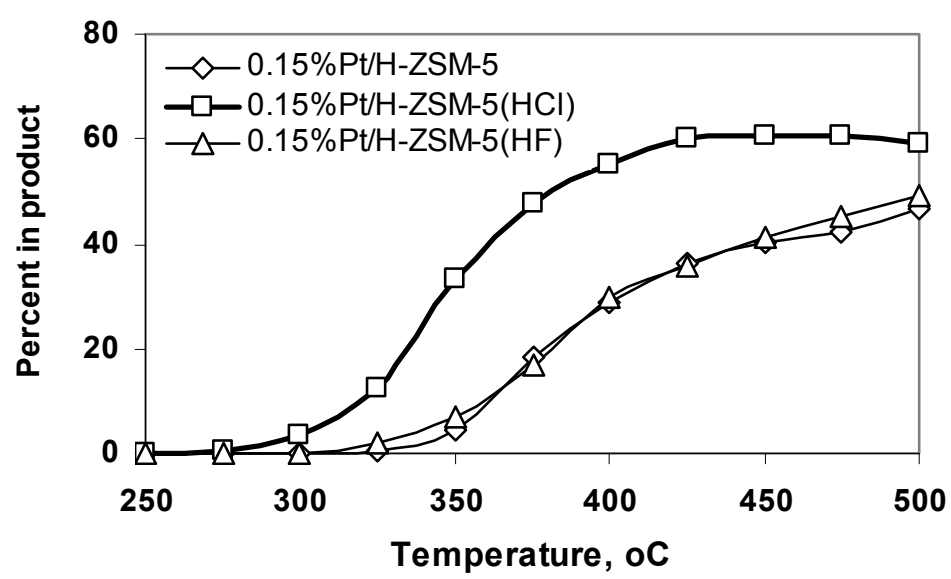

Fig.7. Hydrocracking of $n$-hexane before and after $\mathrm{HCl}$ and $\mathrm{HF}$ treatment of the

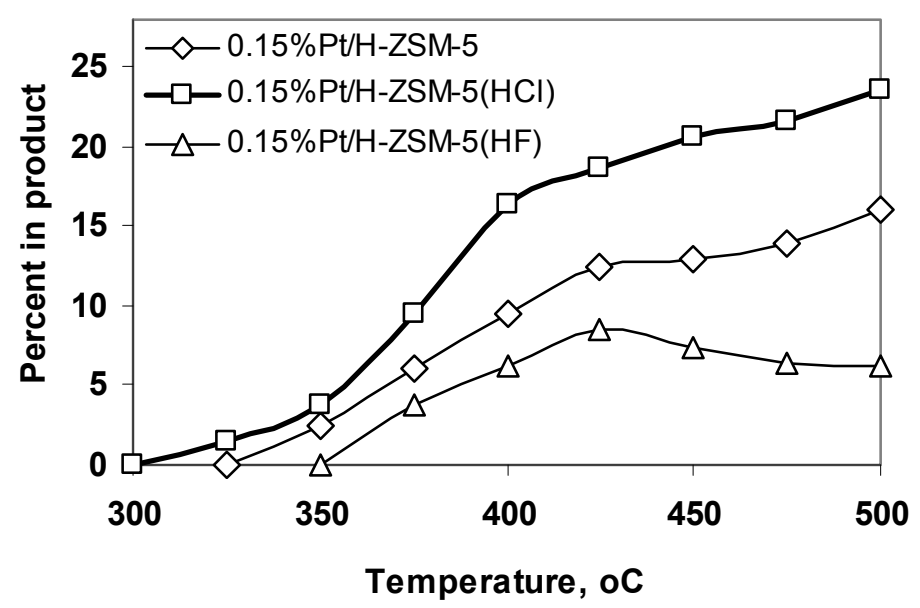

Fig. 8. Dehydrocyclization of $n$-hexane before and after $\mathrm{HCl}$ and $\mathrm{HF}$ treatment of the catalyst 